\title{
A Facile Strategy to Construct PDLLA-PTMEG Network with Triple-Shape Effect via Photo-Cross-Linking of Anthracene Groups
}

Hui Xie, Chuan-Ying Cheng, Lan Du, Cheng-Jie Fan, Xiao-Ying Deng, Ke-Ke Yang* and Yu-Zhong Wang*

Center for Degradable and Flame-Retardant Polymeric Materials (ERCEPM-MoE), State Key Laboratory of Polymer Materials Engineering,

National Engineering Laboratory of Eco-Friendly Polymeric Materials (Sichuan), College of Chemistry, Sichuan University, Chengdu 610064, China.

*E-mail: kkyangscu@ 126.com. 


\section{EXPERIMENTS AND METHODS}

Synthesis of N,N-Bis(2-hydroxyethyl)-9-anthracenemethanamine (BHEAA)

Firstly, 9-bromomethylanthracene (BMA) was synthesized from phosphorus tribromide $\left(\mathrm{PBr}_{3}\right)$ and 9-hydroxymethylanthracene. Secondly, BHEAA was synthesized from BMA and excessive diethanolamine (DEA). The reactions were performed as following routes: 9-hydroxymethylanthracene $(3.0 \mathrm{~g}, 14.4 \mathrm{mmol})$ was suspended in dehydrated toluene $(60 \mathrm{~mL})$ and cooled to $0{ }^{\circ} \mathrm{C}$, then $\mathrm{PBr}_{3}(6.8 \mathrm{~mL}, 72.0$ mmol) was injected into the mixture. The reaction was kept at $0{ }^{\circ} \mathrm{C}$ with vigorous stirring for $2 \mathrm{~h}$ and then slowly warmed to room temperature, during which we can observed that the reaction became homogeneous. To eliminate the unreacted $\mathrm{PBr}_{3}$, saturated $\mathrm{K}_{2} \mathrm{CO}_{3}$ solution was added slowly to the residue until no bubbles generated and the reaction system was neutral $(\mathrm{pH}=7)$. Then separated the phases, collected the organic phase and washed with water and repeated for three times, dried over $\mathrm{Na}_{2} \mathrm{SO}_{4}$ at last. The yellow filtrate was concentrated, and then cooled for crystallization. The BMA was yellow needle-like solid and used in fresh without any treatment. $\mathrm{K}_{2} \mathrm{CO}_{3}$ (17.00 g, $123.2 \mathrm{mmol})$, DEA (7.66 g, $72.9 \mathrm{mmol}), \mathrm{KI}(0.60 \mathrm{~g}, 3.61 \mathrm{mmol})$ were added into a $150 \mathrm{~mL}$ flask and dissolved in DMSO (30 mL), BMA (3.30 g, $12.2 \mathrm{mmol})$ was also dissolved in DMSO (70 mL) and dropped into the former reaction vessel. The reaction was kept at $80{ }^{\circ} \mathrm{C}$ for $4 \mathrm{~h}$. The resulting solution was poured into a large amount of water to give crude BHEAA. The crude BHEAA was then filtered, washed with water, dried, recrystallized from the mixed solvents (ethyl acetate: anisole $=1: 1$, $\mathrm{v} / \mathrm{v})$, and dried in a vacuum oven. 
Synthesis of poly(D,L-lactide) diol (PDLLA)

PDLLA was prepared by the ring-opening polymerization (ROP) of D,L-lactide according to previous works. Firstly, D,L-lactide (30 g, 0.21mol) was put into a glass ampoule which had been flame-dried and equipped with a magnetic stirring bar, and then an exhausting-refilling process was repeated several times. After that, a predetermined amount of $\mathrm{BD}(0.51 \mathrm{~mL}, 5.78 \mathrm{mmol})$ was injected into the glass ampoule. And then, the reaction vessel was immersed into a thermostatic oil bath maintained at $130{ }^{\circ} \mathrm{C}$ with vigorous stirring. Finally, $\mathrm{Sn}(\mathrm{Oct})_{2}(0.83 \mathrm{~mL}, 0.42 \mathrm{mmol})$ was injected into the mixture to initiate the ROP as soon as the reactants were melt completely and the reaction was kept for $24 \mathrm{~h}$ under $130{ }^{\circ} \mathrm{C}$ as well as argon atmosphere to give crude product. The crude PDLLA was purified by precipitation of a chloroform solution in methanol, and dried in a vacuum oven.

\section{Characterization and methods}

Nuclear magnetic resonance (NMR). ${ }^{1} \mathrm{H}-\mathrm{NMR}$ spectra for the synthesized products were recorded by a Bruker AV400 spectrometers (400 Hz, Germany) at room temperature, with deuterated chloroform $\left(\mathrm{CDCl}_{3}\right)$ as solvent and tetramethyl silane (TMS) as an internal reference.

Differential scanning calorimetry (DSC). DSC measurements were performed on a TA instrument DSC Q200 using a steady flow of ultrahigh purity nitrogen purge and an empty aluminum as the reference, over the temperature ranges from $-60{ }^{\circ} \mathrm{C}$ to $190{ }^{\circ} \mathrm{C}$ at a heating (or cooling) rate of $10{ }^{\circ} \mathrm{C} \cdot \mathrm{min}^{-1}$. 
Dynamic mechanical analysis (DMA). The dynamic mechanical properties of the samples were conducted on the tension film clamp of a dynamic mechanical analyzer DMA Q800 (TA Instruments, USA) with a heating rate of $3{ }^{\circ} \mathrm{C} \cdot \mathrm{min}^{-1}$ from $-100{ }^{\circ} \mathrm{C}$ to $100{ }^{\circ} \mathrm{C}$ at a frequency of $1 \mathrm{~Hz}$. The storage modulus $\left(E^{\prime}\right)$ and Loss factor $(\tan \delta)$ were tested.

Static tensile tests. The Young's Modulus $(E)$, tensile strength $\left(\sigma_{\mathrm{m}}\right)$ and elongation at break $\left(\varepsilon_{\mathrm{b}}\right)$ of all the samples were investigated through an Instron Universal Testing Machine (Model 5567, Instron Corp, MA, USA) at a crosshead speed of $20 \mathrm{~mm} \mathrm{~min}^{-1}$ at room temperature. The sizes of specimens were about $4 \mathrm{~mm} \times 0.13 \mathrm{~mm}$ (width $\times$ thickness) and the length of the sample between the two pneumatic grips of the testing machine was $20 \mathrm{~mm}$. Five dumbbell-shaped specimens were tested in each group.

Gel permeation chromatography (GPC). The molecular weight $\left(M_{\mathrm{w}}, M_{\mathrm{n}}\right.$ and polydispersity index $M_{\mathrm{w}} / M_{\mathrm{n}}$ ) of AN-PDLLA-PTMEG was analyzed by GPC. The test was carried out with a HLC-8320 system (Tosoh Corporation, Japan) equipped with a refractive index detector and two columns, a TSK gel super HZM-M and a TSK gel SuperHZ3000. Tetrahydrofuran (THF) acted as elution solvent with a flow rate of 0.6 $\mathrm{mL} \cdot \mathrm{min}^{-1}$ at $40{ }^{\circ} \mathrm{C}$ and a polystyrene standard was used for calibration. 